\title{
A test for the convexity of human well-being over the life cycle: longitudinal evidence from a 20-year panel
}

Citation for published version (APA):

van Landeghem, B. G. M. (2011). A test for the convexity of human well-being over the life cycle: longitudinal evidence from a 20-year panel. ROA. ROA Research Memoranda No. 8 https://doi.org/10.26481/umaror.2011008

Document status and date:

Published: 01/01/2011

DOI:

10.26481/umaror.2011008

Document Version:

Publisher's PDF, also known as Version of record

\section{Please check the document version of this publication:}

- A submitted manuscript is the version of the article upon submission and before peer-review. There can be important differences between the submitted version and the official published version of record.

People interested in the research are advised to contact the author for the final version of the publication, or visit the DOI to the publisher's website.

- The final author version and the galley proof are versions of the publication after peer review.

- The final published version features the final layout of the paper including the volume, issue and page numbers.

Link to publication

\footnotetext{
General rights rights.

- You may freely distribute the URL identifying the publication in the public portal. please follow below link for the End User Agreement:

www.umlib.nl/taverne-license

Take down policy

If you believe that this document breaches copyright please contact us at:

repository@maastrichtuniversity.nl

providing details and we will investigate your claim.
}

Copyright and moral rights for the publications made accessible in the public portal are retained by the authors and/or other copyright owners and it is a condition of accessing publications that users recognise and abide by the legal requirements associated with these

- Users may download and print one copy of any publication from the public portal for the purpose of private study or research.

- You may not further distribute the material or use it for any profit-making activity or commercial gain

If the publication is distributed under the terms of Article $25 \mathrm{fa}$ of the Dutch Copyright Act, indicated by the "Taverne" license above, 
Maastricht University

Research Centre for Education and the Labour Market | ROA

\section{A Test for the Convexity of Human Well-Being over the Life Cycle: Longitudinal Evidence from a 20-Year Panel}

Bert van Landeghem

\section{ROA Research Memorandum}

ROA-RM-2011/8

Research Centre for Education and the Labour Market Maastricht University

P.O. Box 616,6200 MD Maastricht, The Netherlands

$\mathrm{T}+31433883647 \mathrm{~F}+31433884914$

secretary-roa-sbe@maastrichtuniversity.n www.roa.nl 


\section{A Test for the Convexity of Human Well-Being over the Life Cycle: Longitudinal Evidence from a 20-Year Panel}

Bert van Landeghem

ROA-RM-2011/8*

August 2011

Research Centre for Education and the Labour Market

Maastricht University

P.O. Box 616, 6200 MD Maastricht, The Netherlands

$\mathrm{T}+31433883647 \mathrm{~F}+31433884914$

secretary-roa-sbe@maastrichtuniversity.nl

www.roa.nl

\footnotetext{
* The ROA Research Memorandum Series was created in order to make research results available for discussion, before those results are submitted for publication in journals.
} 


\section{Abstract}

\section{A Test for the Convexity of Human Well-Being over de Life Cycle: Longitudinal Evidence from a 20-Year Panel**}

(Forthcoming in Journal of Economic Behavior and Organization, DOI 10.1016/j. jebo.2011.08.001)

A huge cross-section literature, written by economists and others, argues that human well-being is $U$-shaped through the life cycle. In many cases this U-shape is robust (with as a well-known exception the pattern evident in some U.S. data sets if few independent variables are included). However, a lively debate is currently ongoing about its true shape. This paper discusses the identication problem of age, time, and cohort effects. It suggests a simple way to interpret estimates of age variables in a first-difference framework. Building on McKenzie's (2006) methodology, the paper shows that no extra assumptions are needed in order to identify the second derivative of well-being to age, i.e. to estimate the changes in changes in the actual age and well-being relationship. An empirical application, using a large German data set, finds that human well-being is convex in age until after midlife, which is approximately consistent with a U-shaped pattern through life, and not with the concave relationship sometimes found in U.S. studies.

JEL Classification: C23, I31, J10

Keywords: Life Cycle Happiness; Subjective Well-Being; Birth Cohorts; Time Periods; U-shape

Bert van Landeghem

ROA

Maastricht University

P.O. Box 616

6200 MD Maastricht

The Netherlands

b.vanlandeghem@maastrichtuniversity.nl

and University of Leuven, LICOS Centre for

Institutions and Economic

Performance \& Department of Economics

\footnotetext{
** For discussions and their interest in my work, I thank conference participants of the 8th International German Socio-Economic Panel Users Conference, the 2008 Well-Being Conference, the 4th Italian Congress of Econometrics and Empirical Economics, and the Royal Economic Society 2011 Conference, as well as seminar participants in Bern, Leuven, Maastricht, Rome, and Warwick. I am grateful to Jo Swinnen, Iwan Barankay, Ruxanda Berlinschi, Chris Boyce, Paolo Casini, Frank Cörvers, Geert Dhaene, Alex Dobson, Nicola Fuchs-Schuendeln, David McKenzie, Alessandra Pelloni, Damiaan Persyn, Jan Sauermann, Thijs Vandemoortele, Christoph Wunder, Jim Ziliak, two anonymous referees, and the editor for feedback and fruitful discussions. I also thank Andrew Oswald for valuable advice at various stages of this project. Finally, sincere thanks go to Anneleen Vandeplas, Erwin Ooghe, and Erik Schokkaert for commenting on the more technical details of this paper. A Rubicon grant from the Dutch Organization for Scientic Research (NWO) facilitated the final revisions of the manuscript.
} 


\section{Introduction}

What happens to people's happiness as they age? Many researchers have observed a U-shape of subjective well-being $^{1}$ in age in cross-section samples, generally bottoming out between the late 30s and early 50s. This pattern has been found both for developed countries (Blanchflower and Oswald, 2004; Clark and Oswald, 1996; Di Tella et al., 2001, 2003; Oswald, 1994; Oswald and Powdthavee, 2007, 2008a,b; Winkelmann and Winkelmann, 1998), as well as for transitioning and developing countries (Fafchamps and Shilpi, 2008; Powdthavee, 2003, 2005; Sanfey and Teksoz, 2007; Senik, 2004). From a psychologist's perspective, Mroczek and Spiro (2005) find that positive affect follows an inverse U-shape over the life cycle. However, their sample only includes individuals from age 40 and above.

During the last decade, a stream of subjective well-being research has emerged in the economics literature addressing a wide variety of questions. ${ }^{2}$ Age has often been introduced as a control, and did not obtain much attention as such until recently. ${ }^{3}$ Blanchflower and Oswald (2008) document extensive cross-country evidence on the pattern of well-being over the life cycle, finding a U-shaped relationship in nearly all countries after controlling for some standard covariates. In a follow-up study, Blanchflower and Oswald (2009) show that this U-shaped relationship occurs not only when adding standard controls to the regression specification, but also quite commonly emerges in raw data. Some recent research also documents cross-country evidence of a second turning point in life around the age of 75 (Fischer, 2009; Gwozdz and Sousa-Poza, 2010; Mroczek and Spiro, 2005).

Although the U-shape seems to be observable in many countries regardless of the regression specification, public policymakers still may be able to influence the shape of this pattern. Deaton (2010) finds that life satisfaction deteriorates quickly for the elderly in Eastern Europe and the former Soviet Union, while this effect does not seem

\footnotetext{
${ }^{1}$ The terms happiness, subjective well-being, and life satisfaction are used interchangeably in this paper.

${ }^{2}$ See Clark et al. (2008), Di Tella and MacCulloch (2006), Frey and Stutzer (2002), or Graham (2006) for comprehensive overviews.

${ }^{3} \mathrm{~A}$ notable exception is Clark et al. (1996), who elaborate extensively on the pattern of job satisfaction over the life cycle in a single cross-section of the British Household Panel Survey.
} 
to occur (or occurs far less often) for those living in high-income countries. Moreover, it is well-known that the U-shape of well-being over the life cycle in some U.S. data sets only appears distinctly after discounting the effects of income and marital status, and that the pattern is concave and increasing if one does not control for these variables (Easterlin, 2006; Glenn, 2009; Yang, 2008). In data recently collected from 2005 to 2008, however, Oswald and $\mathrm{Wu}$ (forthcoming) find that overall life satisfaction is roughly Ushaped in the U.S. in the raw data as well. Using U.S. cross-sectional data from 2008, this pattern is confirmed by Stone et al. (2010), who find that the U-shaped pattern is robust to control variables added but is sensitive to the measure of well-being analyzed. While a global measure of well-being and positive hedonic well-being both seem to be U-shaped, the patterns are different for negative hedonic well-being variables. Feelings of stress and anger steeply decline from the age of the early 20s, worries increase during midlife and then decline again, and sadness seems to exhibit a flat pattern over the life cycle.

The recent debate on life cycle happiness has often focussed on whether or not counterfactual analyses are more meaningful than unconditional means (Blanchflower and Oswald, 2008, 2009; Easterlin, 2006; Glenn, 2009). Indeed, as Heckman and Robb (1985) point out, age is a crude proxy for other underlying variables. Some researchers prefer to isolate certain of these underlying variables for conceptual reasons, whereas others prefer to favour the pattern in the raw data. At the same time, another somewhat related concern has been matter for debate, namely, whether or not the observed pattern of well-being over the life cycle could be artificial due to birth cohort (and/or time) effects. For example, it might be possible that well-being is constant over the life cycle but that people born in different years report, on average, a different level of life satisfaction. These differing levels of satisfaction might result from the different circumstances in which they were raised, or even from the application of a different rating scale. Hence, two cohorts might be equally happy but still report a different value of life satisfaction. ${ }^{4}$ Authors such as Blanchflower and Oswald (2008, 2009) have already pointed out that longitudinal studies are needed to further investigate this problem. This paper therefore seeks to contribute to the current literature by responding to this need.

\footnotetext{
${ }^{4}$ The different grading systems at universities around the world can serve as an apt illustration. A mark of $75 \%$ would be granted only for very exceptional achievements at a British university, while $85 \%$ at an Italian university reflects only moderate performance.
} 
Several strategies have been proposed to overcome the multicollinearity between age, time, and birth cohort, and the appropriateness of each proposed strategy will depend on the particular context. Heckman and Robb (1985) propose looking at observables that are expected to drive the effects. However, especially in the subjective well-being literature, it is far from clear which underlying variables would be appropriate and sufficient, and it would be more convenient if the effects could be modeled agnostically. Deaton and Paxson (1994a) have suggested another approach in which they assume that time effects are orthogonal to a time trend. In other words, time effects are assumed to be just transitory shocks, and no long-term time trend is expected. This assumption may be reasonable for some applications, but not for others. Steady increases or decreases (or very persistent shocks) in life satisfaction, for example, might be caused by long-term changes in a society's socioeconomic characteristics. In this context, Stevenson and Wolfers (2009) document for the U.S. a decline in female happiness over time (both absolute and relative to male happiness) and leave open the question to which characteristics the phenomenon should be attributed.

In this paper, the analysis will analyze life cycle happiness in a longitudinal setting using data from 24 rounds of the German Socio-Economic Panel (GSOEP) from 1984 to 2007, likely the longest-running panel that includes a life satisfaction question. Inspired by McKenzie (2006), the paper will illustrate that we can still identify the second derivative of well-being to age if one does not want to make any assumptions.

Although the results from the analysis cannot be used to indicate absolutely whether or not well-being is U-shaped over the life cycle, they do tell us that the pattern is convex at least until after midlife, and thus consistent with a U-shaped relationship.

The remainder of this paper is organized as follows. Section 2 presents an overview of how economists have tried to embed life cycle happiness in economic theory. Section 3 tries to illustrate in a didactic way the identification problem, and the assumptions one is (possibly unconsciously) making when modifying the regression specification in order to overcome this identification problem. Eventually, this section shows that without making any assumptions, one can still identify the second derivative of well-being to age. Section 4 briefly documents the data while Section 5 discusses the empirical results. Section 6 concludes. 


\section{Life cycle utility}

Some guidance in the economics literature on the structure of well-being over the life cycle can be provided by the well-known life cycle model.

Consider an agent who lives $T+1$ periods, starting at period 0 and with no endowments. Under standard microeconomic assumptions, instantaneous utility $u$ depends on consumption $C$ and can therefore be written as $u\left(C_{t}\right) .^{5}$

The functional relationship between utility and consumption is assumed to be increasing and concave:

$$
\begin{gathered}
\frac{d u\left(C_{t}\right)}{d C_{t}}>0 \\
\frac{d^{2} u\left(C_{t}\right)}{d C_{t}^{2}}<0 .
\end{gathered}
$$

Furthermore

$$
\begin{aligned}
& \lim _{C_{t} \rightarrow 0} \frac{d u\left(C_{t}\right)}{d C_{t}}=+\infty \\
& \lim _{C_{t} \rightarrow+\infty} \frac{d u\left(C_{t}\right)}{d C_{t}}=0 .
\end{aligned}
$$

It is assumed that an agent (or household) plans its consumption path over a lifetime at the beginning of the life cycle. For each period, a household earns income $Y$ and can choose to save and thus accumulate assets $A$, or to consume more than it earns, implying asset decumulation or even borrowing (consuming future income). After adopting a transversality condition stating that $A_{T}=0$, or that the household leaves neither assets nor debts after the end of life in period $T$, the agent's maximization problem can be formulated as follows:

$$
\max U=\sum_{t=0}^{T} \frac{u\left(C_{t}\right)}{(1+\rho)^{t}} \quad \text { s.t. } \quad \sum_{t=0}^{T} \frac{Y_{t}}{(1+r)^{t}}=\sum_{t=0}^{T} \frac{C_{t}}{(1+r)^{t}}
$$

\footnotetext{
${ }^{5}$ Consumption needs to be seen as an aggregate of many components, and can also include leisure as it is very standard in labour economics.
} 
where $U$ denotes lifetime utility, $\rho \geq 0$ is a discount rate reflecting valuing consumption today more than consumption in the future, and where $r \geq 0$ is a rate of return to capital that equals the savings rate under the assumption of perfect credit markets.

The Lagrangian of the discrete intertemporal maximization problem in Equation (1) can now be formulated as follows:

$$
L\left(C_{0}, \ldots, C_{T}, \lambda\right)=\sum_{t=0}^{T} \frac{u\left(C_{t}\right)}{(1+\rho)^{t}}+\sum_{t=0}^{T} \lambda\left(\frac{Y_{t}-C_{t}}{(1+r)^{t}}\right.
$$

From the first order conditions, it follows that:

$$
u^{\prime}\left(C_{0}\right)=u^{\prime}\left(C_{1}\right) \frac{1+r}{1+\rho}=u^{\prime}\left(C_{2}\right)\left(\frac{1+r}{1+\rho}\right)^{2}=\ldots=u^{\prime}\left(C_{T}\right)\left(\frac{1+r}{1+\rho}\right)^{T}
$$

It is difficult, however, to derive convincing predictions for life cycle happiness from this model for two main reasons.

First, even in this simple framework in which one assumes perfect credit markets, a completely predictable evolution of income, and an unchanging utility function over the life span, microeconomic theory leaves much room for debate regarding the evolution of utility over the life cycle. If $r \gg \rho$, one would expect increasing utility over the life cycle, while the reverse is true if $r \ll \rho$. A flat pattern of utility over the life cycle is expected when the interest rate and the discount rate are equal. More patterns can be simulated when assumptions of the model are altered, for example when liquidity constraints or uncertainty over income are introduced, or when one assumes that the utility function changes as one ages.

Second, it is far from obvious how one should define life satisfaction, and whether it can be proxied accurately with instantaneous utility as modeled in this basic framework. Subjective well-being research has shown that consumption is not the only determinant of one's life satisfaction and that life events such as unemployment, marriage... may play a major role apart from their pecuniary implications, which means that one needs to agree on a set of controls to be included if one would like to use life satisfaction data to test life cycle models. Moreover, the life cycle theory depending on discounted 
utility does not incorporate utility of anticipation (Frederick et al., 2002): future wellbeing might well influence one's current life satisfaction. As discussed in work such as that of Fleurbaey et al. (2009), one must distinguish between decision utility, based on preferences, and a hedonic state. Consider two individuals, one age 20 and one age 80 . Both might agree that life at 20 is better than life at 80 . This does not mean, however, that the 20-year-old is happier than the 80-year-old, as they might have different aspirations. The latter might have learnt to feel happy with his situation. The frequently observed U-shape in life satisfaction thus might well be caused by evolving aspirations. The importance of aspirations on one's life satisfaction has been empirically illustrated in work such as Senik (2008). Kassenboehmer and Haisken-Denew (2008) argue that the U-shaped pattern of subjective well-being over the life cycle might be artificial due to interviewer effects: when being interviewed each year by the same interviewer, one might start to feel more confident over time and give a more honest (possibly lower) evaluation of one's life. However, this does not explain why the U-shape appears in many single cross-sectional data sets as well.

More thoughts on how to model life cycle happiness can be found in work such as Deaton (2010) or Shmanske (1997). As Deaton (2010) puts it:

While it would be a mistake to take these predictions (of the life cycle model) too seriously, they provide a framework for consideration and interpretation.

It seems that data analyses are crucial to understand patterns of life cycle happiness and to ensure the continuing feedback between theory and empirics.

\section{The econometric framework}

\subsection{The set-up of the illustrating data-generating process}

The remainder of this section uses an illustration whereby the number of time periods equals 3 and the number of age groups equals 5. All age groups are represented in all periods. Hence, one observes 7 cohorts. The oldest cohort, Cohort 7, is situated in Age Group 5 in Time Period 1. The youngest cohort, Cohort 1, is situated in Age Group 1 
in Time Period 3. Hence, cohorts can age in and out of the panel. The youngest cohort will only be present in the last period, while the oldest cohort will only be present in the first period. Table 1 shows the cohort for each period-age combination.

Next, consider the following data-generating process:

$$
W B_{j, k}=C S T+A_{j}+T_{k}+C_{l=j-k+3}
$$

with $j=1 \ldots 5, k=1 \ldots 3$ and $l=1 \ldots 7$ subscripts for the age group, the time period and the cohort, respectively. $W B$ denotes well-being, $C S T$ a constant, and $A, T$, and $C$ are age, time, and cohort effects. As an error component is not essential to make the point clear, the data-generating process is assumed to be error-free at all levels during this illustration.

\subsection{The identification problem and identifying first and second derivatives}

Let us consider the regression specification which aims to estimate the data described in the data-generating process of the previous subsection.

$$
W B_{i, j, k}=C S T+\sum_{j=2}^{5} \alpha_{j} a_{j}+\sum_{k=2}^{3} \beta_{k} t_{k}+\sum_{l=1}^{2} \gamma_{l} c_{l}+\sum_{l=4}^{7} \gamma_{l} c_{l}
$$

$a_{j}, t_{k}$, and $c_{l}$ denote the age, time, and cohort dummies, respectively. ${ }^{6} \alpha^{-}, \beta-$, and $\gamma$-symbols are their respective coefficients. The $i$-subscript for the dependent variable must draw attention to the fact that the analysis will be using genuine panel data and not pseudo panel data. ${ }^{7}$

\footnotetext{
${ }^{6}$ The upper case letters refer to the actual effect while the lower case letters refer to the associated dummy. For example, $T_{3}$ refers to the time effect in Time Period 3, while $t_{3}$ refers to the dummy which equals 1 when Time Period 3 is observed.

${ }^{7} \mathrm{~A}$ pseudo panel is a concept introduced by Deaton (1985), and refers to the averaging of repeated cross-sectional data across years and cohorts. One thus observes the same cohort at different points in time. While McKenzie (2006) mainly focusses on technical aspects of inference and estimation in a pseudo panel framework, this paper discusses more extensively the identification problem and the
} 
It is well-known that when estimating a model with a constant and three sets of dummies that are not linearly related, omitting one dummy from each set allows identification. The baseline category in the above specification consists of individuals from Age Group 1 in Time Period 1, but therefore inevitably also from Birth Cohort 3 (see Table 1). Although a dummy from each set is omitted, this model still suffers from a multicollinearity problem. By definition, a cohort equals the age period - the time period +3 , and the three sets of dummies are thus not independent of each other.

Next, one can attempt to estimate the first derivative of well-being to time and age, by differencing the dependent variable across time within the individual, such that the individual fixed effect (including the cohort effect) is eliminated and no longer must be controlled for in the regression specification. ${ }^{8}$

If $\Delta_{t}$ denotes the difference operator over time, one can write the following regression specification:

$$
\Delta_{t} W B_{i, j, k}=\sum_{j=2}^{5} \alpha_{j} a_{j}+\sum_{k=2}^{3} \beta_{k} t_{k} .
$$

For example, $\Delta_{t} W B_{i, 2,2}$ equals $A_{2}-A_{1}+T_{2}-T_{1}$, that is the difference between the age effects of Age Group 2 and Age Group 1, plus the difference between the time effects of Time Period 2 and Time Period 1 (the constant and cohort effect are eliminated). For any $i$ and $k, a_{j}$ equals 1 when the left-hand side of Equation (6) equals $W B_{i, j, k}-W B_{i, j-1, k-1}$, and 0 otherwise. Similarly, for any $i$ and $j, t_{k}$ equals 1 for $W B_{i, j, k}-W B_{i, j-1, k-1}, 0$ otherwise.

Differencing out the cohort effect, however, is not enough to solve the identification problem. To understand this more clearly, let us write the values of the $a_{j}$ and $t_{k}$ as in Equation (6) in matrix form.

interpretation of estimates under different conditions. As the analysis is carried out using genuine panel data and not pseudo panel data, the identification strategy is slightly different than in McKenzie (2006).

${ }^{8}$ One might be interested in the scenario in which both the left-hand side and the right-hand side of Equation (5) are differenced. This scenario is discussed in Appendix 1. 


$$
\begin{aligned}
& \begin{array}{llllll}
t_{2} & t_{3} & a_{2} & a_{3} & a_{4} & a_{5}
\end{array}
\end{aligned}
$$

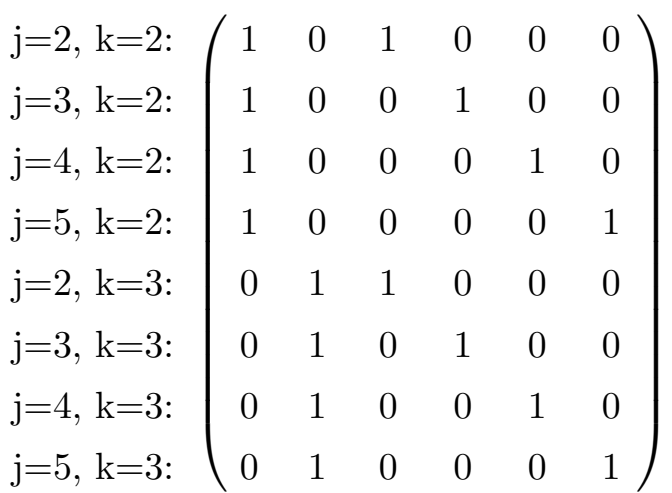

The bordered matrix contains 8 rows, but only 5 of them are linearly independent. For example, by adding $R_{4}-R_{8}$ to $R_{5}, R_{6}$, and $R_{7}$, one obtains $R_{1}, R_{2}$, and $R_{3}$, respectively.

Hence, there are 6 unknown parameters but only 5 linearly independent equations, which means that one has to fix one of the parameters in order to retrieve the others. One can, for example, drop age dummy $a_{2}$, and assume that the age effects $A_{2}$ and $A_{1}$ are equal to each other. The solutions for the $\alpha$ - and $\beta$-parameters are then as follows:

$$
\begin{aligned}
& \beta_{2}=\left(A_{2}-A_{1}\right)+\left(T_{2}-T_{1}\right) \\
& \beta_{3}=\left(A_{2}-A_{1}\right)+\left(T_{3}-T_{2}\right) \\
& \alpha_{3}=\left(A_{3}-A_{2}\right)-\left(A_{2}-A_{1}\right) \\
& \alpha_{4}=\left(A_{4}-A_{3}\right)-\left(A_{2}-A_{1}\right) \\
& \alpha_{5}=\left(A_{5}-A_{4}\right)-\left(A_{2}-A_{1}\right)
\end{aligned}
$$

The solutions for the parameters in (6) illustrate that if the assumption that $A_{1}$ equals $A_{2}$ is correct, the $\beta$-parameters represent the first derivative of well-being to time, and the $\alpha$-parameters the first derivative of well-being to age. If we do not want to make such an assumption, one knows only the first derivative of well-being to time and age up to a constant. One can retrieve the second derivatives without making any assumptions by calculating the difference between $\beta_{k}$ and $\beta_{k-1}$ (for $k=3$ ) on the one hand, and $\alpha_{j}$ and $\alpha_{j-1}$ (for $j=3 \ldots 5$ ) on the other hand. 


\section{Data}

The empirical analysis uses data from the GSOEP, most likely the longest-running household panel that includes a subjective question concerning well-being. The panel runs from 1984 to 2007 for West Germany, and information on East German households is available from 1990 onwards (Wagner et al., 2007). ${ }^{9}$

The subjective question on well-being that is included in the GSOEP is expressed in English as follows: "On a scale from 0 (completely dissatisfied) to 10 (completely satisfied), how satisfied are you with your life, all things considered?"10

The analysis is performed on a total of 44960 individuals. ${ }^{11} 36302$ individuals are observed in West Germany and 9308 in East Germany, and 650 seem to have crossed the border between the two while participating in the panel study. People between 17 years old (the minimum age for being interviewed) and 85 years old, are considered throughout the analysis. Hence, we observe 24 time periods, composed of 69 age groups and 92 cohorts.

\section{Empirical results}

\subsection{Baseline results}

Before discussing results from first-differenced equations, it might be instructive to look at some baseline results obtained from pooled OLS regressions. ${ }^{12}$

\footnotetext{
${ }^{9} 1990$ data are not used for East Germany throughout the analysis as the East German Mark was still in use at that time. As the exchange rate was changing on a daily basis, no reliable estimates for income are available for that year.

${ }^{10}$ Readers concerned whether or not answers to such survey questions offer reliable and valid measures for actual life satisfaction may want to consult Krueger and Schkade (2008) or Oswald and Wu (2010).

${ }^{11}$ Although it is possible to perform the analysis on a slightly higher number of observations for these regressions with fewer explanatory variables, the same set of observations is used throughout the analysis as to prevent results from being driven by different observations rather than by a different specification.

${ }^{12}$ As Ferrer-i-Carbonell and Frijters (2004) have pointed out using the GSOEP, assuming cardinality rather than ordinality of happiness measures is not of great importance for the outcomes. Hence, OLS rather than ordered regressions are used as the former are easier to interpret and to implement, especially in a first-difference framework.
} 
Figure 1 and Figure 2 show us the estimated pattern of subjective well-being over the life cycle for West and East Germany and with a full set of time dummies included, without and with controls, respectively. In Figure 1, the curve for West Germany mildly and steadily declines until the early 50s, and then rises until the age of 68, after which we observe a downward trend again. The curve for East Germany has a more or less similar course, but more irregular than that for West Germany. Moreover, the decline before midlife is much more pronounced in East Germany than in West Germany. The differences in patterns possibly can be explained by different distributions of social conditions among the age groups between West and East. Alternatively, the omission of cohort effects might cloud the results differently for East compared with West. Including control variables causes no dramatic change in the observed pattern, as one sometimes finds in U.S. data after controlling for marital status and income. It thus seems that changes of these variables across time periods, age groups, or cohorts do far less influence the estimated pattern of well-being over the life cycle in Germany than it is the case in some U.S. data sets. The inclusion of controls reduces, however, the discrepancy for the two curves after midlife.

Figure 3 and Figure 4 show similar regressions, as shown in Figure 1 and Figure 2, but now a full set of cohort dummies is included instead of a full set of time dummies. The graphs show that, at least to some extent, the results are sensitive to this switch in specification. In Figure 3, for West Germany, the decline in well-being at older ages is now more pronounced than in Figure 1, and this decline starts earlier in life as well. In East Germany, the decline in well-being before the turning point is now less pronounced (and less regular) than in Figure 1. While the curve of East Germany runs below the West's curve for the whole course of life in Figure 1, one observes a crossing of the curves in Figure 3 at the early 50s, after which East Germans are enjoying higher life satisfaction than do West Germans. After including some standard controls, the West's and East's curve run more or less parallel again: the isolation of standard controls again makes the discrepancy between West and East somewhat smaller. The more we control for socioeconomic variables, the more uniform appear the estimated agewell-being patterns. Nevertheless, there remain some differences between Figure 2 and Figure 4. In Figure 2, the West's curve declines from the beginning, while the same 
curve initially slopes upward in Figure 4. For East Germany, the curve is somewhat constant early in life in Figure 2, but upward sloping in Figure 4.

The sensitivity of estimated life cycle patterns to the regression specification is wellknown in the economics literature. Heathcote et al. (2005) find that estimations of the course of inequality over the life cycle can vary considerably under the assumption of either the absence of cohort effects or the absence of time effects. They thereby criticize Deaton and Paxson (1994b) who make abstraction of time effects and thus leave out time dummies. Hall et al. (2007) illustrate with simulated data how biases arise when making the wrong assumptions.

\section{$5.2 \quad$ First-difference results}

Figure 5 shows us the first derivative of well-being to age estimated in a first-difference framework, for West and East Germany. The course of the curves is quite irregular but slightly upward sloping until the age of 55. Both curves decline again after midlife. An upward sloping first derivative up to after midlife, meaning a positive second derivative, is consistent with a U-shape.

As explained in Section 3.2, the first derivative is known only up to a constant. To illustrate this, Figure 6 shows us estimates (carried out on the full sample) of the first derivative of well-being to age from three different regression specifications. Age dummy $a_{2}$, age dummy $a_{41}$ and time dummy $t_{10}$ have been omitted, respectively. Results show that the curves run parallel to each other, but that they do not necessarily coincide.

As has also been pointed out in Section 3.2, it is still possible to calculate the second derivative of well-being to age without making any assumptions, by subtracting $a_{j-1}$ from $a_{j}$ for all $j=3 \ldots 69$. The results are visualized in Figure 7, and show that the second derivative of well-being to age for both West and East Germany is more or less identical. The second derivative is mostly positive up to after midlife. A positive second derivative implies convexity, which is in line with a U-shaped pattern and not with a concave pattern sometimes found in U.S. data. Results do not predict a smooth curve, but one should also keep in mind that the analysis requires a lot from the data, as the specification is as flexible as possible. Random noise is probably an important explanation for the 
irregularities seen in the curves. Appendix 2 discusses a more parsimonious regression, which is less demanding for the data.

The first-difference results allow us not only to calculate and graph the second derivative, but also allow us to carry out the following formal test. $\left(\alpha_{j}-\alpha_{j-1}\right)=\left(\alpha_{j-1}-\alpha_{j-2}\right)$ with $j=3 \ldots 69$. As one may remember from Section $4, j=3$ corresponds to 19-yearolds, and $j=69$ to 85 -year-olds. Rejecting this hypothesis means that a quadratic is not sufficient to capture the actual age--well-being relationship between the age groups $j-2$ to $j$. For West Germany, the above hypothesis can be rejected for age ranges 51-54, 57-59, 64-66 and 75-80 with P-values ranging from 0.006 to 0.11. In East Germany, a quadratic relationship can be rejected between ages 54-59 and 63-73 with P-values ranging from 0.0005 to 0.11 .

\section{Conclusion}

Recently, economists and other social scientists have been concerned about well-being patterns over the life cycle. A lively debate has been occurring that concerns whether or not regressions should contain control variables, and how researchers should approach the challenge of disentangling age, time, and cohort effects. This paper has focussed mainly on the latter issue. It has been possible to study second derivatives rather than the actual effects themselves by using longitudinal data. Although the latter might be more informative, the methodology applied in this paper, inspired by McKenzie (2006), allows identification without making further assumptions.

Using data from the GSOEP, the empirical analysis finds that changes in age effects increase over the life cycle, and eventually decrease after midlife. A convex relationship between age and well-being up to the 50s would be in line with the commonly found Ushaped age-well-being pattern in these and other data in pooled cross-sectional analyses. Of course, the results do not exclude many other patterns. Nevertheless, one can exclude the concavely upward sloping pattern, which is often documented in the literature for U.S. data when few controls are included in the regression specification. Hence, the empirical results of this paper at least suggest that the latter pattern is not universal across the world. 
To establish firm insights in the actual age-well-being relationship, it would seem prudent to examine this pattern in as many data sets for as many countries as possible, and furthermore, to develop a convincing conceptual framework in order to overcome the multicollinearity problem by modeling at least one out of the three variables (time, age or cohort) by underlying variables.

\section{References}

Attanasio, O., 1993. A cohort analysis of saving behavior by U.S. households. NBER Working Papers No. 4454, National Bureau of Economic Research.

Blanchflower, D., Oswald, A., 2004. Well-being over time in Britain and the USA. Journal of Public Economics 88, 1359-1386.

Blanchflower, D., Oswald, A., 2008. Is well-being U-shaped over the life cycle? Social Science and Medicine 66, 1733-1749.

Blanchflower, D., Oswald, A., 2009. The U-shape without controls: A response to Glenn. Social Science and Medicine 69, 486-488.

Clark, A., Frijters, P., Shields, M., 2008. Relative income, happiness, and utility: An explanation for the Easterlin paradox and other puzzles. Journal of Economic Literature 46, 95-144.

Clark, A., Oswald, a., 1996. Satisfaction and comparison income. Journal of Public Economics 61, 359-381.

Clark, A., Oswald, A., Warr, P., 1996. Is job satisfaction U-shaped in age? Journal of Occupational and Organizational Psychology 69, 57-81.

Deaton, A., 1985. Panel data from time series of cross-sections. Journal of Econometrics 30, 109-126.

Deaton, A., 2010. Income, aging, health, and well-being around the world: Evidence from the Gallup World Poll. in: Research Findings in the Economics of Aging, NBER Chapters, 235-263. 
Deaton, A., Paxson, c., 1994a. Saving, growth and aging in Taiwan. in: Studies in the Economics of Aging, NBER Chapters, 331-362.

Deaton, A., Paxson, C., 1994b. Intertemporal choice and inequality. Journal of Political Economy 102, 437-467.

Di Tella, R., MacCulloch, R., 2006. Some uses of happiness data in economics. Journal of Economic Perspectives 20, 25-46.

Di Tella, R., MacCulloch, R., Oswald, A., 2001. Preferences over inflation and unemployment: Evidence from surveys of happiness. American Economic Review 91, 335-341.

Di Tella, R., MacCulloch, R., Oswald, A., 2003. The macroeconomics of happiness. Review of Economics and Statistics 85, 809-827.

Easterlin, R., 2006. Life cycle happiness and its sources. Intersections of psychology, economics, and demography. Journal of Economic Psychology 27, 463-482.

Fafchamps, M., Shilpi, F., 2008. Subjective welfare, isolation, and relative consumption. Journal of Development Economics 86, 43-60.

Ferrer-i-Carbonell, A., Frijters, P., 2004. How important is methodology for the estimates of the determinants of happiness? Economic Journal 114, 641-659.

Fleurbaey, M., Schokkaert, E., Decancq, K., 2009. What good is happiness? CORE Discussion Papers No. 2009/017, Université Catholique de Louvain.

Frederick, S., Loewenstein, G., O'donoghue, T., 2002. Time discounting and time preference: A critical review. Journal of Economic Literature 40, 351-401.

Frey, B., Stutzer, A., 2002. What can economists learn from happiness research? Journal of Economic Literature 40, 402-435.

Fischer, J., 2009. Happiness and age cycles - return to start... MPRA Paper No. 15249, University of Munich.

Gardner, J., Oswald, A., 2004. How is mortality affected by money, marriage, and stress? Journal of Health Economics 23, 1181-1207. 
Glenn, N., 2009. Is the apparent U-shape of well-being over the life course a result of inappropriate use of control variables? A commentary on Blanchflower and Oswald (66:8, 2008, 1733-1749). Social Science and Medicine 69, 481-485.

Graham, C., 2006. Insights on development from the economics of happiness. World Bank Research Observer 21, 233-257.

Guven, C., Saloumidis, R., 2009. Why is the world getting older? The influence of happiness on mortality. Economics Series 2009/03, Deakin University.

Gwozdz, W., Sousa-Poza, a., 2010. Ageing, health and life satisfaction of the oldest old: An analysis for Germany. Social Indicators Research 97, 397-417.

Hall, B., Mairesse, J., Turner, L., 2007. Identifying age, cohort and period effects in scientific research productivity: Discussion and illustration using simulated and actual data on French physicists. Economics of Innovation and New Technology 16, 159-177.

Heathcote, J., Storesletten, K., Violante, G., 2005. Two views of inequality over the life cycle. Journal of the European Economic Association 3, 765-775.

Heckman, J., Robb, R., 1985. Using longitudinal data to estimate age, period, and cohort effects in earnings equations. in Mason and Fienberg, eds. Cohort Analysis in Social Research, New York: Springer-Verlag.

Kassenboehmer, S., Haisken-Denew, j., 2008. Heresy or enlightenment? The wellbeing age U-shape is really flat! mimeo, RWI Essen.

Krueger, A., Schkade, D., 2008. The reliability of subjective well-being measures. Journal of Public Economics 92, 1833-1845.

McKenzie, D., 2006. Disentangling age, cohort and time effects in the additive model. Oxford Bulletin of Economics and Statistics 68, 473-495.

Mroczek, D., Spiro, A., 2005. Change in life satisfaction during adulthood: Findings from the Veterans Affairs Normative Aging Study. Journal of Personality and Social Psychology 88, 189-202. 
Oswald, A., 1994. Happiness and economic performance. Economic Journal 107, 1815-1831.

Oswald, A., Powdthavee, N., 2007. Obesity, unhappiness and the challenge of affluence: Theory and evidence. Economic Journal 117, 441-454.

Oswald, A., Powdthavee, N., 2008a. Does happiness adapt? A longitudinal study of disability with implications for economists and judges. Journal of Public Economics 92, 1061-1077.

Oswald, A., Powdthavee, N., 2008b. Death, happiness, and the calculation of compensatory damages. Journal of Legal Studies 37, S217-S251.

Oswald, A., Wu, S., 2010. Objective confirmation of subjective measures of human well-being: Evidence from the U.S.A. Science 327, 576-580.

Oswald, A., Wu, S., (forthcoming). Well-being across America. Review of Economics and Statistics.

Powdthavee, N., 2003. Is the structure of happiness equations the same in poor and rich countries? The case of South Africa. Development and Comp Systems, EconWPA.

Powdthavee, N., 2005. Unhappiness and crime: Evidence from South Africa. Economica $72,531-547$.

Sanfey, P., Teksoz, U., 2007. Does transition make you happy? Economics of Transition 15, 707-731.

Senik, C., 2004. When information dominates comparison. Learning from Russian subjective panel data. Journal of Public Economics 88, 2099-2123.

Senik, C., 2008. Is man doomed to progress? Journal of Economic Behavior and Organization 68, 140-152.

Shmanske, S., 1997. Life-cycle happiness in a discounted utility model. Kyklos 50, $383-407$.

Stevenson, B., Wolfers, J., 2009. The paradox of declining female happiness. NBER Working Papers No. 14969, National Bureau of Economic Research. 
Stone, A., Schwartz, J., Broderick, J., Deaton, A., 2010. A snapshot of the age distribution of psychological well-being in the United States. Proceedings of the National Academy of Sciences of the United States of America 107, 9985-9990.

Wagner, G., Frick, J., Schupp, J., 2007. The German Socio-Economic Panel Study (SOEP) - Scope, evolution and enhancements. Schmollers Jahrbuch 127, 139-169.

Winkelmann, L., Winkelmann, R., 1998. Why are the unemployed so unhappy? Evidence from panel data. Economica 65, 1-15.

Yang, Y., 2008. Social inequalities in happiness in the United States, 1972 to 2004: An age-period-cohort analysis. American Sociological Review 73, 204-226. 


\section{Appendix 1: Transforming age and time dummies in the first-difference framework}

Let us start again from the example with 5 age groups, 3 time periods, and 7 cohorts outlined in Section 3.1. As for the first-difference framework, one might wonder what happens if one transforms the time dummies and age dummies as well, along with the dependent variable, and hence we estimate the following equation:

$$
\Delta_{t} W B_{i, j, k}=\sum_{j=2}^{5} \alpha_{j} \Delta_{t} a_{j}+\sum_{k=2}^{3} \beta_{k} \Delta_{t} t_{k} .
$$

Differenced age and time dummies take values of $-1,0$, and 1. If, for a particular observation, differenced time dummy $\Delta_{t} t_{k}=1$, it follows that $\Delta_{t} t_{k-1}=-1$. In this example, an observation made in Time Period 3 will have $\Delta_{t} t_{3}$ equal to 1 , and $\Delta_{t} t_{2}$ equal to -1 . In Time Period 2, $\Delta_{t} t_{2}$ equals 1 and $\Delta_{t} t_{3}$ equals 0 . The values of the differenced age dummies $\Delta_{t} a_{j}$ can be summarized as follows:

\begin{tabular}{ccccc}
\hline & $\Delta_{t} a_{2}$ & $\Delta_{t} a_{3}$ & $\Delta_{t} a_{4}$ & $\Delta_{t} a_{5}$ \\
\hline Age $=2$ & 1 & 0 & 0 & 0 \\
Age $=3$ & -1 & 1 & 0 & 0 \\
Age $=4$ & 0 & -1 & 1 & 0 \\
Age $=5$ & 0 & 0 & -1 & 1 \\
\hline
\end{tabular}

The matrix in (10) shows us the values for the $\Delta t_{k}$ and $\Delta_{t} a_{j}$ variables as in Equation (9). 


$$
\begin{aligned}
& \begin{array}{cccccc}
\Delta_{t} t_{2} & \Delta_{t} t_{3} & \Delta_{t} a_{2} & \Delta_{t} a_{3} & \Delta_{t} a_{4} & \Delta_{t} a_{5}
\end{array}
\end{aligned}
$$

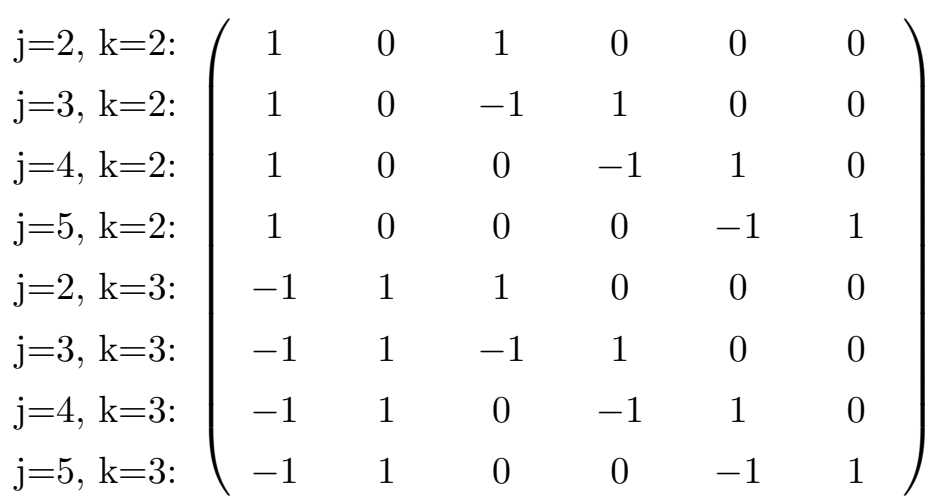

Again, only 5 out of the 8 rows are linearly independent, and thus we are again forced to fix one of the 6 parameters in order to identify the other 5 . If we drop $\Delta_{t} a_{2}$, which means assuming that the age effects for ages 1 and 2 are equal, one obtains the following solution for the remaining parameters:

$$
\begin{array}{ccc}
\beta_{2}= & \left(A_{2}-A_{1}\right)+\left(T_{2}-T_{1}\right) \\
\beta_{3}= & 2\left(A_{2}-A_{1}\right)+\left(T_{3}-T_{2}\right)+\left(T_{2}-T_{1}\right) \\
\alpha_{3}= & \left(A_{3}-A_{2}\right)-\left(A_{2}-A_{1}\right) \\
\alpha_{4}= & \left(A_{4}-A_{3}\right)+\left(A_{3}-A_{2}\right)-2 *\left(A_{2}-A_{1}\right) \\
\alpha_{5}= & \left(A_{5}-A_{4}\right)+\left(A_{4}-A_{3}\right)+\left(A_{3}-A_{2}\right)-3 *\left(A_{2}-A_{1}\right)
\end{array}
$$

Without a loss of generality, one can set $A_{1}$ and $T_{1}$ equal to 0 (the benchmark). The solution for the $\alpha$ - and $\beta$-parameters can then be written as follows:

$$
\begin{aligned}
\beta_{2} & =A_{2}+T_{2} \\
\beta_{3} & =2 A_{2}+T_{3} \\
\alpha_{3} & =A_{3}-A_{2} \\
\alpha_{4} & =A_{4}-2 A_{2} \\
\alpha_{5} & =A_{5}-3 A_{2}
\end{aligned}
$$

We thus obtain the actual curvature of well-being over time and over the life cycle instead of the first derivative, under the condition that the normalization assumption is 
correct, hence if $A_{2}$ equals 0 as well. An incorrect normalization will not only vertically shift the curves up or down, but will also alter their slope. 


\section{Appendix 2: A more parsimonious regression specifi- cation to retrieve second derivatives}

The curves in Figures 5 to 7 do not reveal smooth patterns, and a reader might find it hard to interpret them. One should remember that the regression specifications require much from the data, as the most flexible specification has been requested. Inspired by Attanasio (1993), let us turn to a more parsimonious model and estimate a regression of the form:

$$
\Delta_{t} a g e_{i, k}^{2}+\alpha_{3} \Delta_{t} a g e_{i, k}^{3}+\sum_{k=2}^{24}\left(\beta_{k} \Delta_{t} t_{k}\right)+X^{\prime} \delta
$$

This specification includes differenced higher order terms of age instead of age dummies, and assumes that well-being evolves rather smoothly over the life cycle, seemingly, a natural assumption. It is important to note that the less flexible specification is useful in order to require less of the data, and that it is not a necessary intervention to overcome a structural identification problem. The specification in Equation (13) does not contain a linear age term. Indeed, differencing a linear age term leaves us with a constant, as does the differencing of a linear time term. A linear age trend is therefore indistinguishable from a linear time trend.

Once $\alpha_{2}$ and $\alpha_{3}$ are known, one can use them to draw the first derivative of well-being to age up to a constant.

$$
\frac{d(W B)}{d(a g e)}=C S T+2 * \alpha_{2} * a g e+3 * \alpha_{3} * a g e^{2}
$$

where $C S T$ is unknown. The second derivative can then be computed as:

$$
\frac{d^{2}(W B)}{d(a g e)^{2}}=2 * \alpha_{2}+6 * \alpha_{3} * \text { age. }
$$

The calculations of the second derivative are graphically represented in Figure 8 for West and East Germany. For West Germany, the age at which the second derivative 
switches from positive to negative, or put otherwise, the age at which the first derivative switches from upward sloping to downward sloping, is estimated at 47. This result is in line with a decline in life satisfaction before midlife with a decreasing pace, and an increase in life satisfaction after midlife, also with a decreasing pace. The hypothesis that the second derivative between the age of 20 and the age of 47 is equal to 0 can be rejected at all significance levels with a Wald statistic of 11.78 .

The curves for West and East Germany depicting the second derivative of well-being to age are indistinguishable from each other. For East Germany, the switch from a positive to a negative second derivative occurs at the age of 47.5. The null hypothesis that the second derivative of well-being to age equals 0 between the age of 20 and 47.5 can be rejected at all significance levels with a Wald test of 6.11. 
Table 1: An Overview of Cohorts For Each Period-Age Combination

\begin{tabular}{llllll}
\hline & Age $=1$ & Age $=2$ & Age = 3 & Age =4 & Age = 5 \\
\hline Time $=1$ & Cohort 3 & Cohort 4 & Cohort 5 & Cohort 6 & Cohort 7 \\
Time = 2 & Cohort 2 & Cohort 3 & Cohort 4 & Cohort 5 & Cohort 6 \\
Time =3 & Cohort 1 & Cohort 2 & Cohort 3 & Cohort 4 & Cohort 5 \\
\hline
\end{tabular}


Figure 1: Subjective Well-Being and Age: Pooled OLS Results, a Full Set of Time Dummies Included

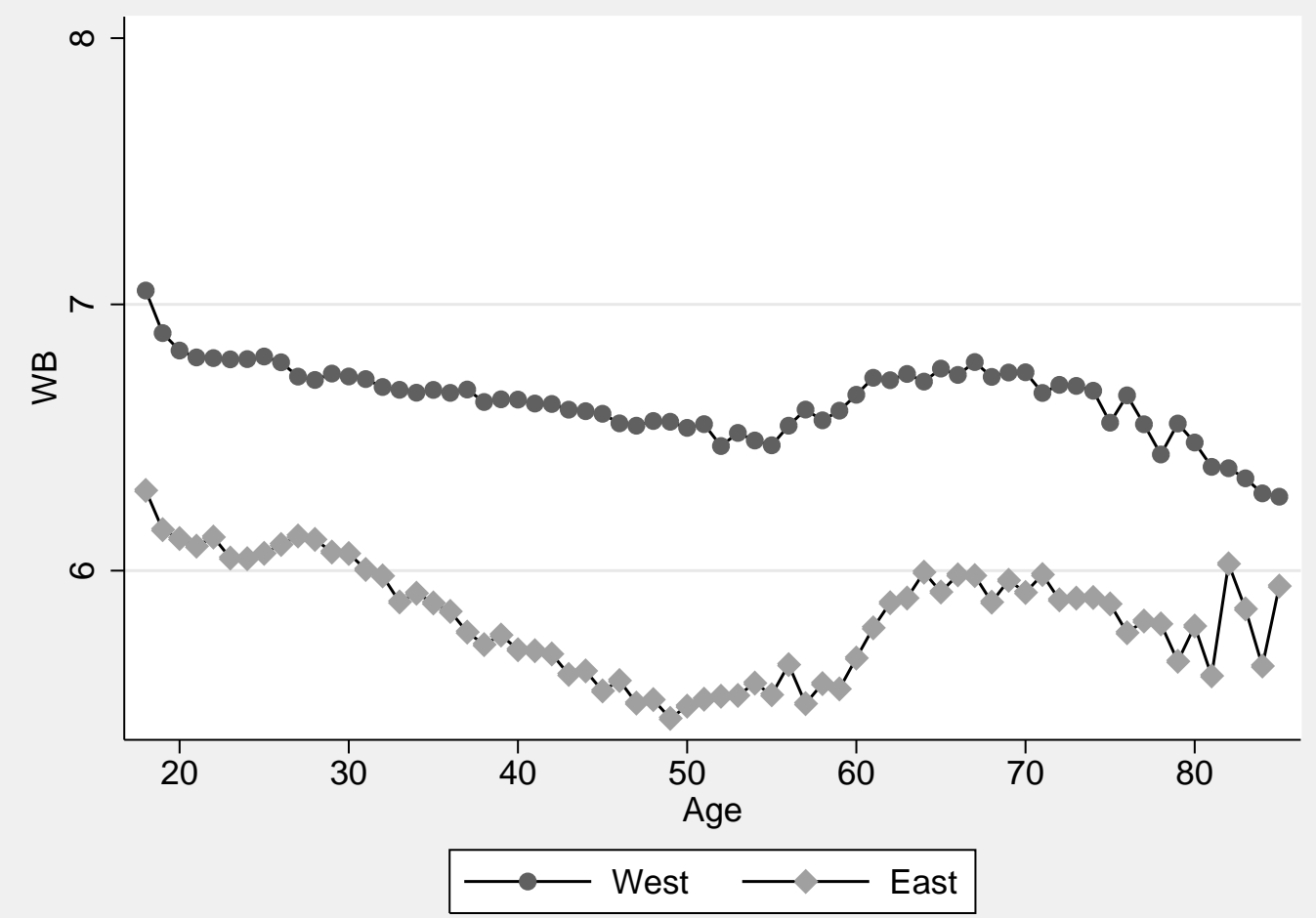

$$
W B=\sum_{j=2}^{69} a_{j} \alpha_{j}+\sum_{k=2}^{24} t_{k} \beta_{k}
$$


Figure 2: Subjective Well-Being and Age: Pooled OLS Results, Standard Controls and a Full Set of Time Dummies Included

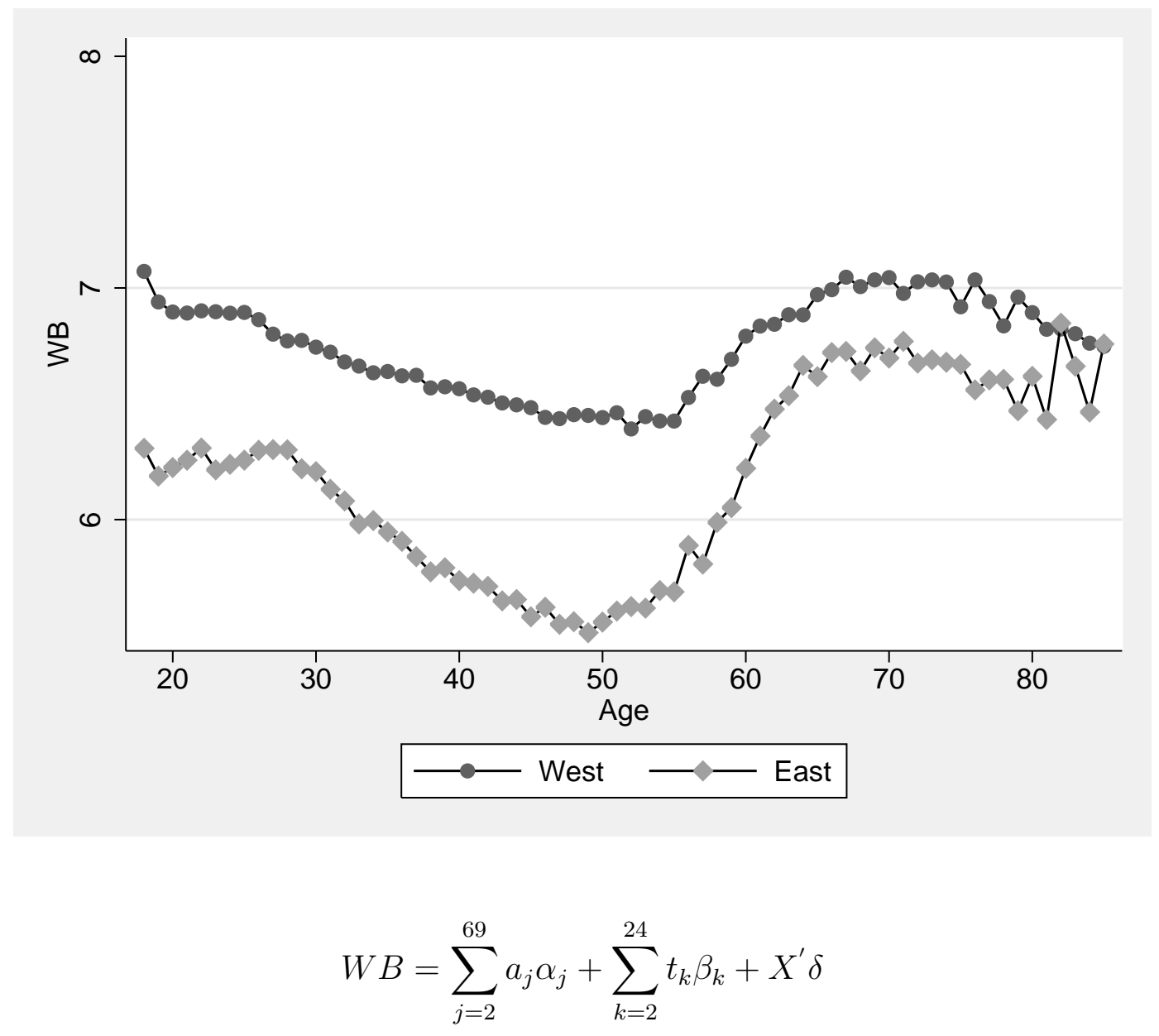

Standard controls include labour force dummies, marital status dummies, and income. 
Figure 3: Subjective Well-Being and Age: Pooled OLS Results, a Full Set of Year-ofBirth Dummies Included

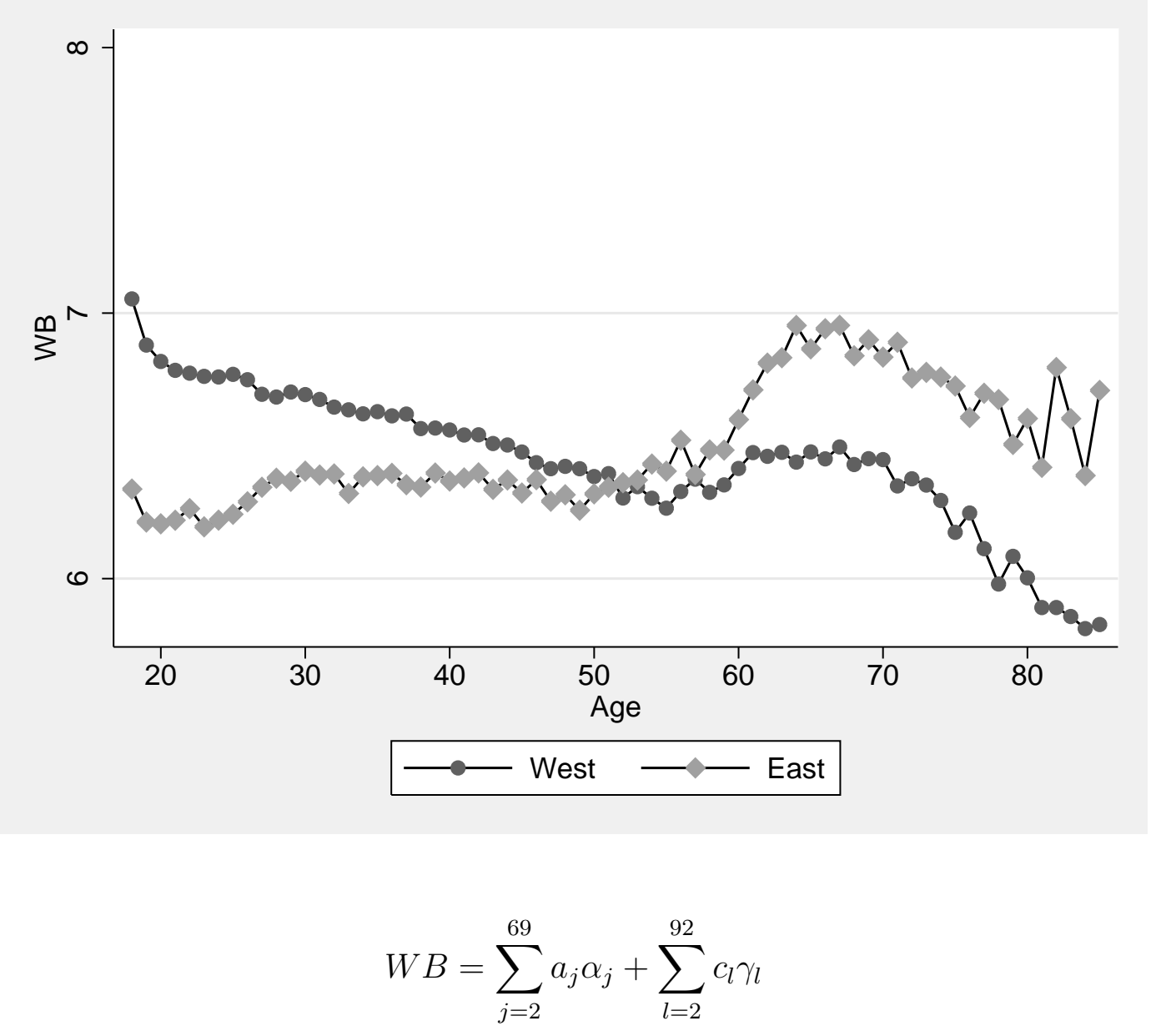


Figure 4: Subjective Well-Being and Age: Pooled OLS Results, Standard Controls and a Full Set of Year-of-Birth Dummies Included

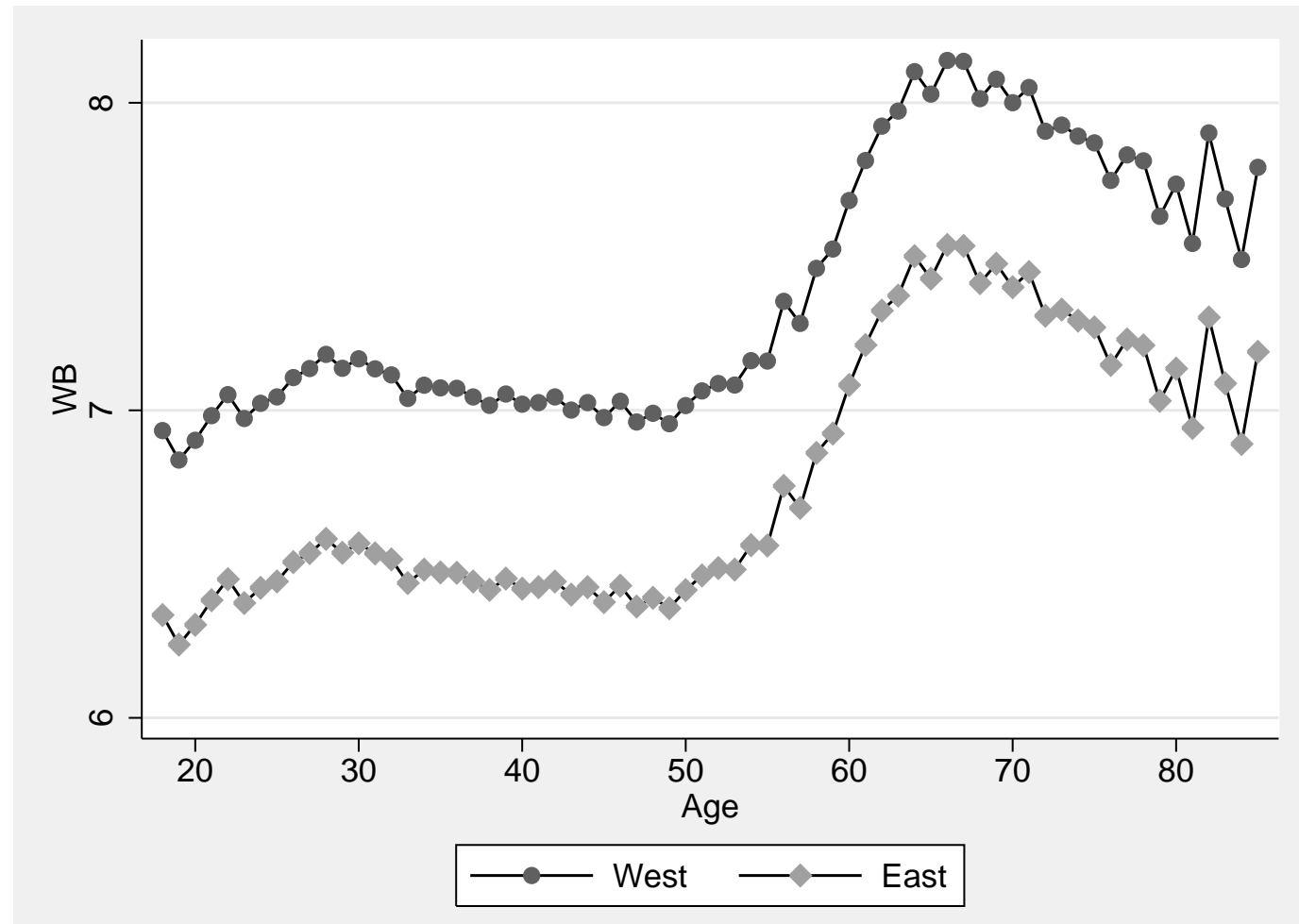

$$
W B=\sum_{j=2}^{69} a_{j} \alpha_{j}+\sum_{l=2}^{92} c_{l} \gamma_{l}+X^{\prime} \delta
$$


Figure 5: Subjective Well-Being and Age: Estimating the First Derivative in a FirstDifference Framework, Some Standard Controls Included

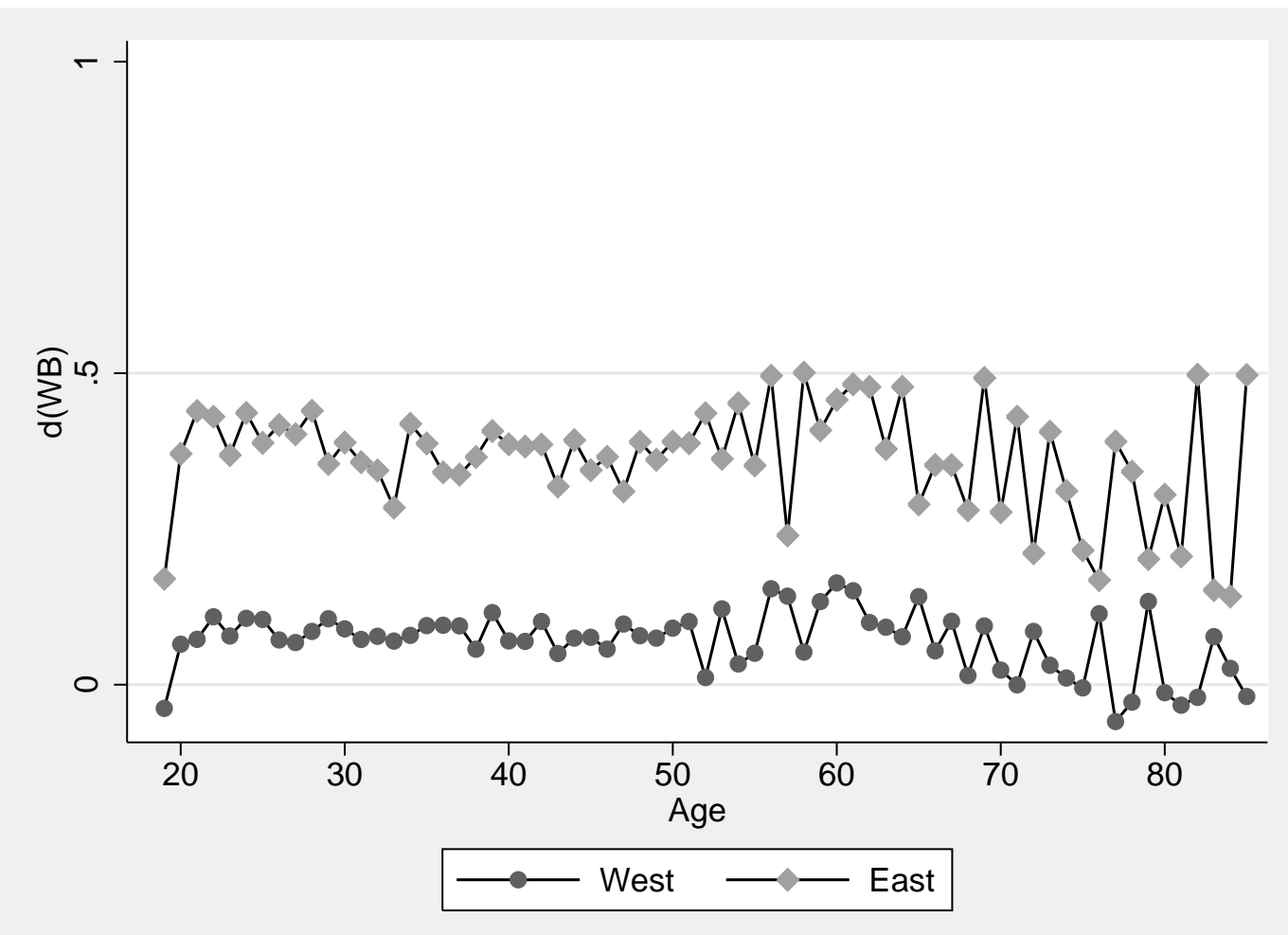

$$
\Delta_{t} W B=\sum_{j=3}^{69} a_{j} \alpha_{j}+\sum_{k=2}^{24} t_{k} \beta_{k}+X^{\prime} \delta
$$


Figure 6: Subjective Well-Being and Age: Estimating the First Derivative under Different Normalization Assumptions, Standard Controls Included

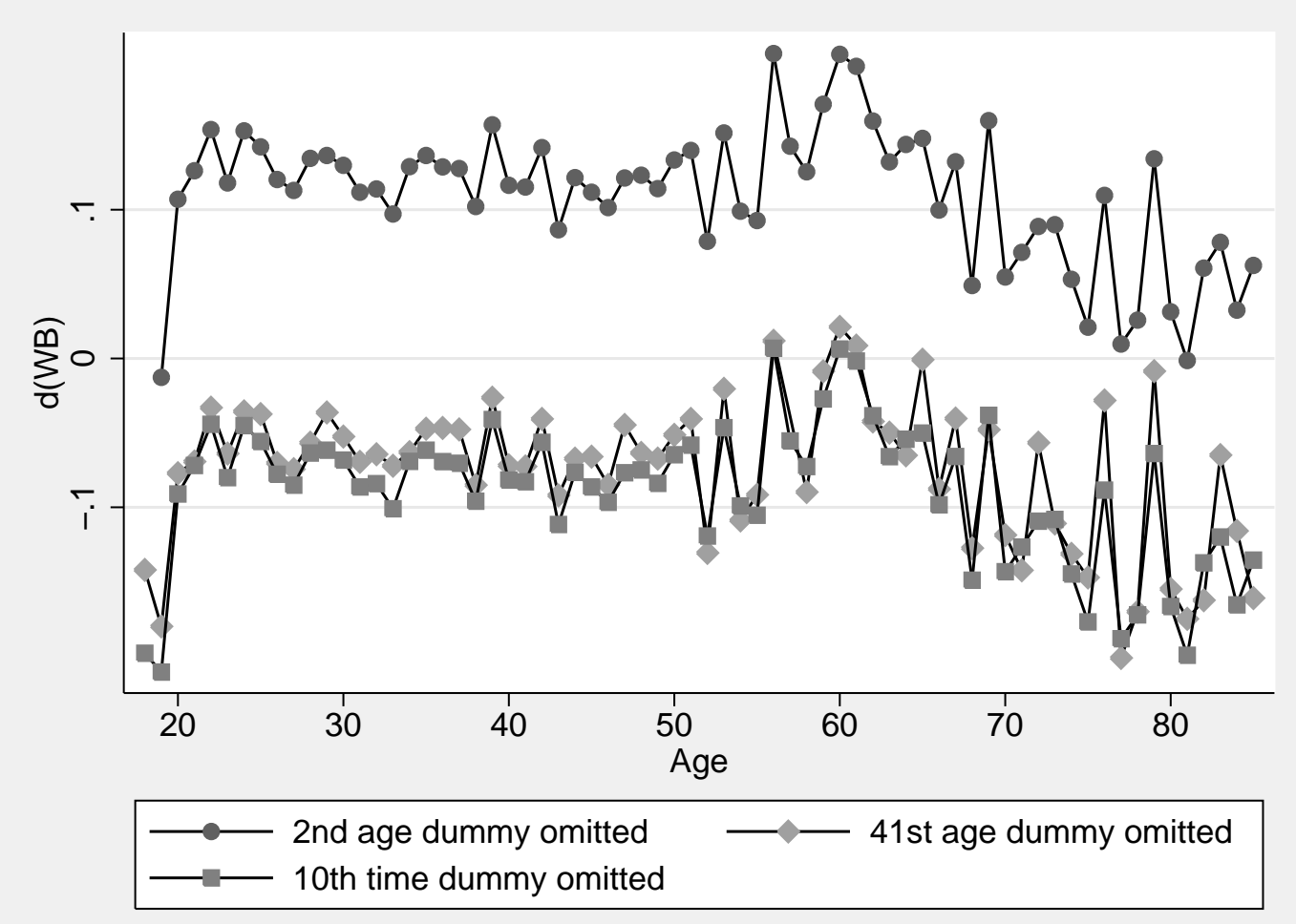


Figure 7: A Graphical Representation of the Second Derivative of Well-Being to Age

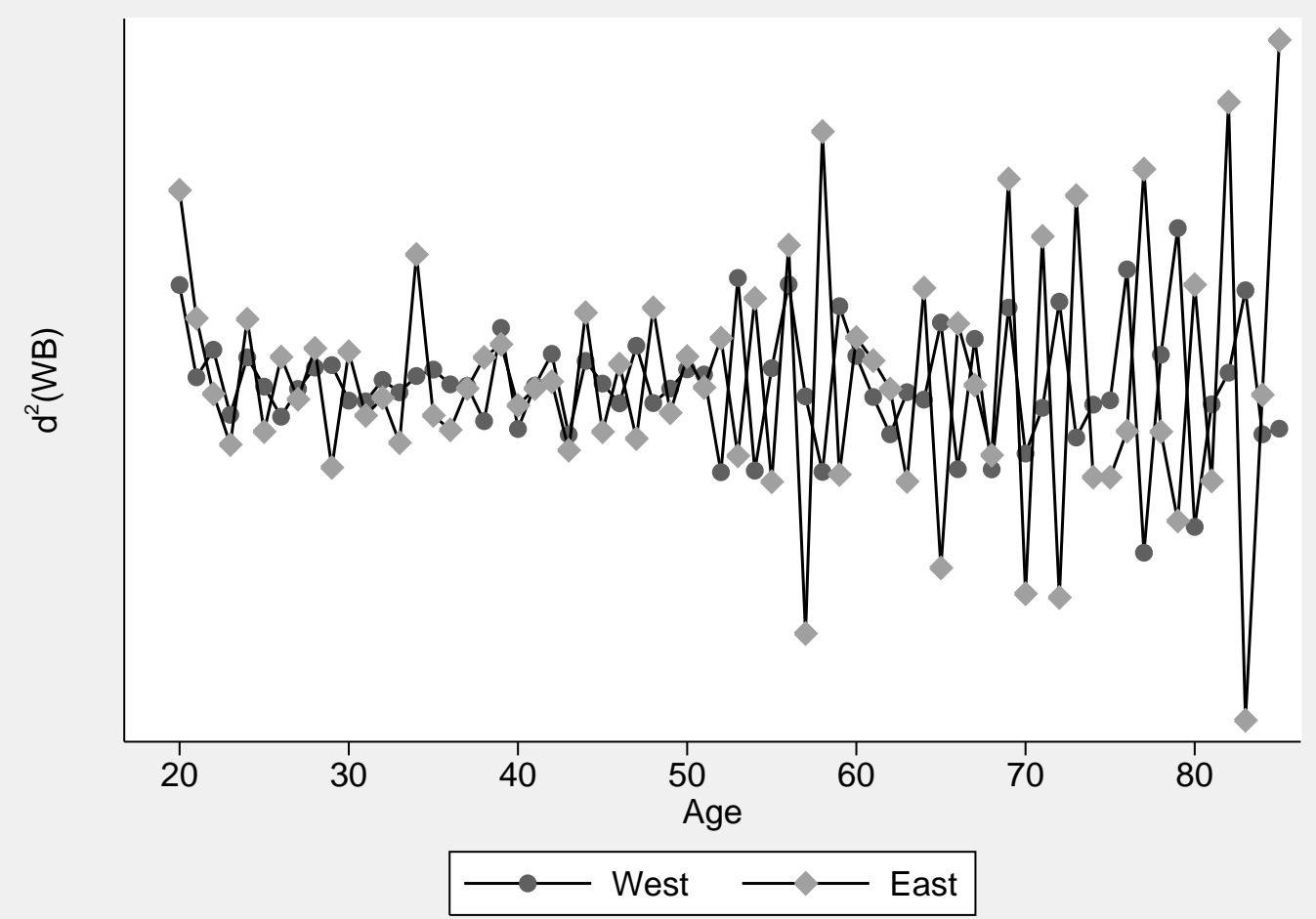


Figure 8: A Graphical Representation of the Second Derivative of Well-Being to Age Derived from a More Parsimonious Model

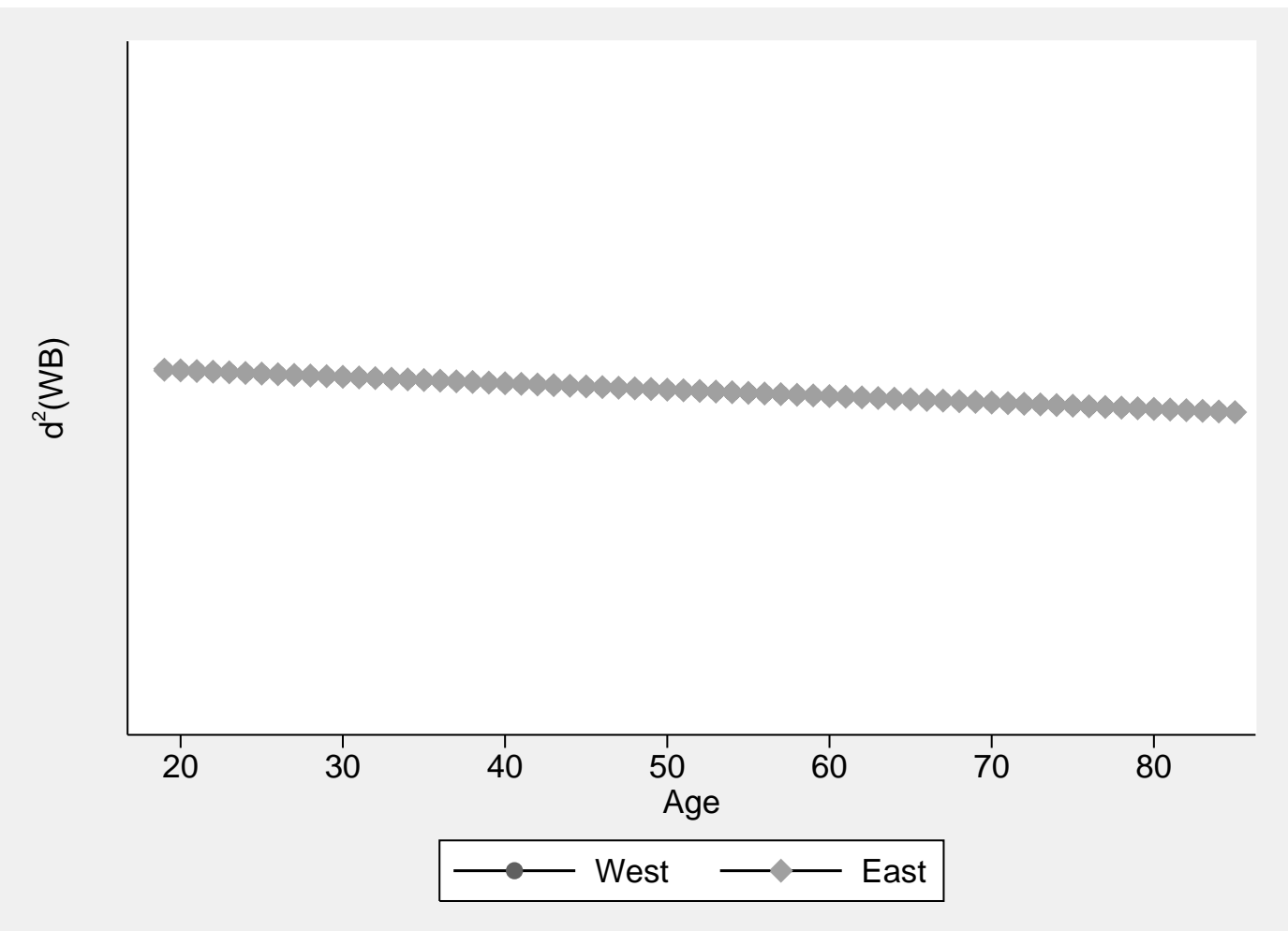

